\title{
О.В. ШУЛЯРЕНКО
}

\section{СРАВНЕНИЕ ТОТАЛЬНОЙ ЭКСТРАПЕРИТОНЕАЛЬНОЙ И ТРАНСАБДОМИНАЛЬНОЙ ПРЕПЕРИТОНЕАЛЬНОЙ ПЛАСТИКИ ПАХОВОЙ ГРЫЖИ}

Национальная медицинская академия последипломного образования имени П.Л. Шупика, г. Киев,

\author{
Украина
}

Цель. Сравнить ранние результаты тотальной экстраперитонеальной и трансабдоминальной преперитонеальной пластики первичной паховой грыжи

Материал и методы. Проанализированы результаты оперативного лечения 47 пациентов, прооперированных в клинике кафедры хирургии и сосудистой хирургии с 2014 по 2016 год по поводу односторонней первичной неосложненной паховой грыжи. Все пациенты, мужчины, были разделены на две группы: в I (25 пациентов) была выполнена тотальная экстраперитонеальная пластика паховой грыжи по разработанному способу тотальной экстраперитонеальной пластики, во II (22 человека) была произведена трансабдоминальная преперитонеальная пластика. Возраст пациентов варьировал от 20 до 61 года, средний возраст в I группе составил 39,3 года, во II - 38,1.

Результаты. Средняя длительность оперативного вмешательства в I группе составила 36,4 минуты, во II - 37,8. Выраженность болевого синдрома по визуальной аналоговой шкале составила в I группе в среднем 1,8 балла, во II - 2,3. Болевой синдром, при котором необходимо использовать ненаркотические анальгетики, продолжался в среднем 2,3 суток в I группе и 2,5 суток во II. Необходимости в использовании наркотических анальгетиков не возникало.

В I группе хорошие ранние результаты были у 21 (84\%) пациента, удовлетворительные - у 4 (16\%), во II группе хорошие ранние результаты были у 11 (50\%), удовлетворительные - у 11 (50\%) пациентов.

Заключение. Предложенный способ тотальной экстраперитонеальной пластики паховой грыжи является операцией выбора для пациентов с грыжей 2, 3a и 3b типа по Nyhus. Хороших ранних результатов хирургического лечения паховой грыжи в группе тотальной экстраперитонеальной пластики первичной паховой грыжи было на $34 \%$ больше, чем в группе трансабдоминальной преперитонеальной.

Ключевые слова: паховая грыжа, герниопластика, сетка, хирургия, операция, ранние результаты, болевой синдром, Nyhus классификация

Objectives. To compare the early results of total extraperitoneal and transabdominal preperitoneal primary herniaplasty.

Methods. Treatment results of patients $(n=47)$ operated on in the clinic of the department of surgery and vascular surgery (2014-2016) due to the unilateral primary uncomplicated hernia have been analyzed. All patients (males) are divided into two groups: the $1^{\text {st }}(n=25)$ group - the total extraperitoneal inguinal hernia repair by the developed method has been performed, the $2^{\text {nd }}(n=22)$ group - the transabdominal preperitoneal herniaplasty has been made. The patients' age varied from 20 to 61 years, the average age in the $1^{\text {st }}$ group was 39,3 years, in the $2^{\text {nd }}-38,1$.

Results. An average operation time in the $1^{\text {st }}$ group made up 36,4 minutes, in the $2^{\text {nd }}-37,8$. The level of pain syndrome according to the Visual Analogue Scale for Pain was 1,8 scores in the first group, 2,3 scores - in the second one. The pain syndrome which requires non-narcotic analgesics lasted 2,3 days in the $1^{\text {st }}$ group and 2,5 days in the $2^{\text {nd }}$ one. There were no indications for narcotic analgesics. In the $1^{\text {st }}$ group the good early results were observed in $21(84 \%)$ patients, satisfactory - in $4(16 \%)$, in the $2^{\text {nd }}$ group the good early results were registered in $11(50 \%)$, satisfactory - in $11(50 \%)$ patients.

Conclusion. The proposed method of the total extraperitoneal inguinal herniaplasty is considered to be an operation of choice for inguinal hernias (2, 3A and 3B types) based on the Nyhus classification. The good early results were $34 \%$ higher in the total extraperitoneal inguinal herniaplasty group than in the transabdominal preperitoneal primary herniaplasty group.

Keywords: inguinal hernia, herniaplasty, mesh, surgery, operation, early results, pain syndrome, Nyhus classification

Novosti Khirurgii. 2016 Nov-Dec; Vol 24 (6): 546-550

Comparison of Total Extraperitoneal and Transabdominal Preperitoneal Inguinal Herniaplasty O.V. Shulyarenko

\section{Введение}

Неоперированная грыжа постепенно увеличивается в размерах, причиняет боль, возникает косметический дефект. Чем больше время гернионосительства, тем более сложное, как правило, оперативное вмешательство необходимо выполнить. В хирургическом лечении грыж брюшной стенки ведущие позиции заняла ненатяжная пластика с имплантацией сетчатого 
эндопротеза, что позволило существенно улучшить результаты и в несколько раз уменьшить частоту рецидивов $[1,2,3]$.

Универсального способа герниопластики на сегодняшний день не существует и, возможно, не будет, поскольку грыжи по образованию и возникновению не идентичны [4].

С начала 1990-х годов лапароскопическая хирургия паховой грыжи развивается как безопасный и эффективный способ, но для нее необходимы более дорогостоящие, чем для открытой хирургии, инструменты и в большинстве случаев общая анестезия $[3,5]$. К преимуществам лапароскопической пластики паховой грыжи следует отнести косметичность, минимальную травматизацию элементов передней брюшной стенки, отсутствие натяжения тканей, преперитонеальное расположение импланта, которое перекрывает места возможного возникновения косой, прямой, бедренной грыжи, соответствие современным принципам «хирургии быстрого выздоровления» $[6,7,8,9]$.

Цель. Сравнить ранние результаты тотальной экстраперитонеальной и трансабдоминальной преперитонеальной пластики первичной паховой грыжи.

\section{Материал и методы}

С 2014 до 2016 года в клинике кафедры хирургии и сосудистой хирургии (Киевская городская клиническая больница №8, клиника «Медиком») было прооперировано 47 мужчин с первичной неосложненной односторонней паховой грыжей, поступивших в плановом порядке.

Bсе пациенты, мужчины, были разделены на две группы: в I группе (25 пациентов) была выполнена тотальная экстраперитонеальная пластика паховой грыжи по разработанному способу тотальной экстраперитонеальной пластики, во II группе (22 человека) была произведена трансабдоминальная преперитонеальная пластика. Рандомизация пациентов осуществлена по типу случайного распределения [10].

Возраст пациентов варьировал от 20 до 61 года, средний возраст в I группе составил $39,3 \pm 2,1$ года $(\mathrm{M} \pm \mathrm{m})$, во II $-38,1 \pm 2,2(\mathrm{M} \pm \mathrm{m})$. При статистическом анализе с использованием критерия Стьюдента различия между группами по возрасту отсутствовали (p>0,1).

В работе использовалась классификация Leoyd M. Nyhus для оценки распределения пациентов по размерам грыжевых ворот [7]. Статистически значимых различий по расположению грыж, типу, размеру грыжевых ворот по Nyhus в I и II группе не выявлено (таблица 1).

Предоперационное обследование включало общеклиническое лабораторное обследование, ультразвуковое исследование органов брюшной полости и забрюшинного пространства, электрокардиографию, по показаниям - определение показателей функции внешнего дыхания, фиброэзофагогастродуоденоскопию, обзорную рентгенографию органов грудной клетки, консультацию смежных специалистов.

Пациентам в I группе (25 пациентов) была выполнена тотальная экстраперитонеальная пластика паховой грыжи в соответствии с разработанным способом тотальной экстраперитонеальной пластики, на который получен Декларационный патент Украины на полезную модель №102998 от 25.11.2015 года, бюл. №22 [11]. Данный способ выполнялся в два этапа.

Под спинальной анестезией производился поперечный разрез кожи и подкожной клетчатки до 1,5 см под пупком. Гемостаз во время всей операции производился эндозажимом, подсоединенным к биполярному электросварочному аппарату. Использовался биполярный электросварочный аппарат «Патонмед ЕКВ3 300» в режиме «коагуляция». Апоневроз выделялся и рассекался в поперечном направлении на протяжении 1,5 см. В предбрюшинное пространство вводилось балонное устройство, направленное к лонному сочленению, и отслаивалась париетальная брюшина от передней брюшной стенки инсуффляцией воздуха в полость балона. После удаления балонного устройства в разрез вводился троакар диаметром 12 мм с лапароскопом. В случае нарушения целостности брюшины производилась сварка ее краев эндозажимом, подсоединенным к биполярному электросварочному аппарату. Образованная полость поддерживалась инсуффляцией в нее CO2 под давлением 12 мм рт. ст. На середине расстояния между пупком и лоном по средин-

Таблица 1

Распределение грыж в зависимости от расположения, типа, размера грыжевых ворот по Nyhus в I и II групाт

\begin{tabular}{lcc}
\hline & I группа & II группа \\
\hline Правосторонняя & $14(44 \%)$ & $12(45 \%)$ \\
Левосторонняя & $11(56 \%)$ & $10(55 \%)$ \\
Косая & $18(72 \%)$ & $17(77 \%)$ \\
Прямая & $7(28 \%)$ & $5(23 \%)$ \\
Тип 2 по Nyhus & $9(36 \%)$ & $8(36 \%)$ \\
Тип 3а по Nyhus & $7(28 \%)$ & $5(23 \%)$ \\
Тип 3b по Nyhus & $9(36 \%)$ & $9(41 \%)$ \\
\multicolumn{2}{c}{$\chi^{2}$} & $>0,05$ \\
Примечание: $\mathrm{p}^{2}-$ критерий $\chi^{2}$ Пирсона. \\
\multicolumn{2}{c}{}
\end{tabular}


ной линии вводился первый рабочий троакар диаметром 5 миллиметров на 1 сантиметр медиально и кверху от передней верхней ости подвздошной кости, выделялась лобковая кость, паховая связка, элементы семенного канатика, куперова связка и нижние эпигастральные сосуды. Потом в предбрюшинное пространство через 12-миллиметровый троакар вводился имплант самофиксирующейся полурассасывающейся сетки из полипропиленовой мононити, свернутый сверху и снизу к срединной линии, размерами $15 \times 9$ см, он проталкивался эндозажимом. Имплант устанавливался таким образом, чтобы он укрывал зоны образования прямой, косой и бедренной грыж. Троакары удалялись. На рану под пупком накладывались 1-2 шва. Накладывалась асептическая повязка.

В послеоперационном периоде проводилась антибиотикопрофилактика цефалоспорином II поколения одноразово.

Первое отличие предложенного способа состоит в использовании импланта: самофиксирующейся полурассасывающейся сетки из полипропиленовой мононити размерами $15 \times 9$ см. Срок ее рассасывания - 15 месяцев. Имплант выкраивался индивидуально, в зависимости от размеров пахового промежутка и индивидуальных анатомических особенностей углов крепления поперечной и внутренней косой мышц живота. Прочность самофиксации крючками позволяла дополнительно не подшивать сетку. Такое расположение импланта обеспечивало более надежную защиту задней стенки пахового канала.

Второе отличие состоит в том, что благодаря значительно более надежному гемостазу вследствие использования биполярного электросварочного аппарата наружное дренирование предбрюшинного или другого пространства не было нужно и не производилось.

Третье отличие состоит в том, что в случае нарушения целостности брюшины последняя надежно сваривалась эндозажимом, подсоединенным к биполярному сварочному аппарату.

Bo II группе (22 пациента) была произведена трансабдоминальная преперитонеальная герниопластика [8].

Профилактика возможных тромботических осложнений в послерперационном периоде проводилась низкомолекулярным гепарином с учетом степени риска. Всем пациентам в послеоперационном периоде проводилась ранняя активизация.

Оценка результатов оперативного лечения пациентов проведена в раннем (до одной недели после операции) послеоперационном периоде. Для оценки эффективности оперативного лечения пациентов обеих групп использовали следующие критерии: средняя длительность оперативного вмешательства, выраженность болевого синдрома по 10-балльной визуальной аналоговой шкале, длительность болевого синдрома, длительность пребывания в стационаре, частота послеоперационных осложнений.

К неудовлетворительным результатам принято относить ситуации, требующие повторного оперативного вмешательства. Результаты, при которых прооперированные пациенты отмечали боль, которая возникала спорадически и исчезала самостоятельно, а также неприятные ощущения в области послеоперационного рубца, считали удовлетворительными.

При статистической обработке использовался пакет программ Statistica for Windows 6.1. Использовали среднюю арифметическую - M; среднюю ошибку средней арифметической $\mathrm{m} ; \mathrm{t}$ - критерий Стьюдента. Статистически достоверным считали отличие при $p<0,05$. Для сравнения достоверности различий дискретных переменных использовали критерий Пирсона $\chi^{2}$. Различия считали статистически значимыми при $\mathrm{p}<0,05$.

\section{Результаты}

Средняя длительность оперативного вмешательства в I группе составила $36,4 \pm 0,02$ $(\mathrm{M} \pm \mathrm{m})$ минуты, во II $-37,8 \pm 0,04(\mathrm{M} \pm \mathrm{m})$. Различия достоверны $(\mathrm{p}<0,05)$.

У 5 (20\%) пациентов первой и у 4 (18\%) пациентов второй группы впереди грыжевого мешка располагалась липома, которая была выделена и удалена.

Выраженность болевого синдрома по 10-балльной визуальной аналоговой шкале составила в первой группе в среднем $1,8 \pm 0,06$ $(\mathrm{M} \pm \mathrm{m})$ балла, во второй $-2,3 \pm 0,1(\mathrm{M} \pm \mathrm{m})$. Различия достоверны $(\mathrm{p}<0,05)$.

Болевой синдром, при котором необходимо использовать ненаркотические анальгетики, продолжался в среднем $2,3 \pm 0,13(\mathrm{M} \pm \mathrm{m})$ суток в первой группе и $2,5 \pm 0,21(\mathrm{M} \pm \mathrm{m})$ суток во второй. Различия статистически не значимы $(\mathrm{p}>0,1)$. Необходимости в использовании наркотических аналгетиков не возникало. Длительность пребывания в стационаре составила $24,92 \pm 0,4(\mathrm{M} \pm \mathrm{m})$ часа в первой группе и $25 \pm 0,51(\mathrm{M} \pm \mathrm{m})$ часа - во второй. Различия статистически не значимы ( $>0,1)$.

В первой группе у 1 (4\%) пациента в раннем послеоперационном периоде развилась пневмония, у 2 (8\%) возникла задержка мочи, обусловленная хроническим простатитом, оба случая были успешно вылечены консервативно. 


\begin{tabular}{|c|c|c|}
\hline \multicolumn{3}{|c|}{$\begin{array}{c}\text { Таблица } 2 \\
\text { Ранние результаты хирургического лечения } \\
\text { в I и II группе }\end{array}$} \\
\hline & I группа & II группа \\
\hline Хорошие & $21(84 \%)$ & $11(50 \%)$ \\
\hline Удовлетворительные & $4(16 \%)$ & $11(50 \%)$ \\
\hline Неудовлетворительные & - & - \\
\hline $\mathrm{p} \chi^{2}$ & $<0,05$ & \\
\hline
\end{tabular}

Во второй группе у $1(4,5 \%)$ пациента образовалась подкожная серома в области постановки троакара, у 1 (4,5\%) - подкожная гематома, которые были раздренированы пункционно, достигнут гемостаз, у $1(4,5 \%)$ пациента возникла задержка мочи, обусловленная хроническим простатитом

Ранние результаты хирургического лечения в сравниваемых группах представлены в таблице 2.

\section{Обсуждение}

По возрасту, расположению грыжи и распределению в зависимости от размера грыжевых ворот по классификации L.M. Nyhus группы были сопоставимы. Статистически значимых различий между обеими группами по длительности послеоперационного болевого синдрома, при котором необходимо использовать ненаркотические анальгетики, а также по длительности пребывания в стационаре не было выявлено. Средняя длительность оперативного вмешательства во II группе была больше, чем в I. Выраженность болевого синдрома в среднем во II группе была больше, чем в I.

Согласны с H. Lau [12], что преперитонеальное расположение сетки не является причиной каких-либо нарушений в работе мочевыводящих путей.

Разделяем мнение R. Bittner et al. [13], что в случае косой грыжи при наличии большого и измененного в связи с предыдущими странгуляциями грыжевого мешка целесообразно идентифицировать сосуды семенного канатика перед выделением лобковой кости, паховой связки, куперовой связки и нижних эпигастральных сосудов, что позволит избежать возможного повреждения элементов семенного канатика.

Поддерживаем точку зрения некоторых авторов [13, 14, 15], что липомы, которые располагаются впереди грыжевого мешка, должны быть выделены и удалены, потому что они в последующем могут вызывать симптомы, характерные для рецидивной грыжи.

Трансабдоминальная преперитонеальная пластика паховой грыжи предусматривает уста- новку инструментов в брюшную полость, что, в отличие от тотальной экстраперитонеальной пластики, сопряжено с возможным возникновением спаек в брюшной полости.

\section{Выводы}

1. Предложенный способ тотальной экстраперитонеальной пластики паховой грыжи является операцией выбора для пациентов с грыжей 2, 3a и 3b типа по Nyhus.

2. Хороших ранних результатов хирургического лечения паховой грыжи в группе тотальной экстраперитонеальной пластики первичной паховой грыжи было на $34 \%$ больше, чем в группе трансабдоминальной преперитонеальной.

\section{ЛИТЕРАТУРА}

1. Аверьянов МЮ, Гаар ЕВ, Горохов ВН. Сравнительный анализ применения ненатяжных и традиционных способов герниопластики при грыжах живота. Соврем Технологии в Медицине. 2011;(3):39-43. 2. Винник ЮС, Петрушко СИ, Горбунов НС, Назарьянц ЮА. Оперативное лечение грыж передней брюшной стенки. Красноярск, РФ; 2011. 260 с. 3. Saclarides TJ, Myers JA, Millican KA, eds. Common surgical diseases: an algorithmic approach to problem solving. 3-rd ed. New York, US: Springer; 2015. 363 p. 4. Николаев НЕ, Алексеев СА. Классификация, этиопатогенез и выбор способов хирургического лечения паховой грыжи. Здравоохранение. 2014;(12):36-39.

5. Визгалов СА, Смотрин СМ. Паховые грыжи: современные аспекты этиопатогенеза и лечения. Журн Гродн Гос Мед Ун-та. 2010;(4):17-22.

6. Пиневич ДЛ, Суконко ОГ, Полякова СЛ, Смирнов ВМ, Минич АА. Принципы «хирургии ускоренного выздоровления». Здравоохранение. 2014;(5):34-48.

7. Ничитайло МЕ, Булик ИИ. Современные аспекты эндовидеохирургического лечения сложных и рецидивних паховых грыж. Клін Хірургія. 2010;(3):10-16.

8. Жебровский ВВ. Хирургия грыж живота. Москва, РФ: Мед информ агентство; 2005. 384 с.

9. Tam KW, Liang HH, Chai CY. Outcomes of staple fixation of mesh versus nonfixation in laparoscopic total extraperitoneal inguinal repair: a meta-analysis of randomized controlled trials. World J Surg. 2010 Dec;34(12):3065-74. doi: 10.1007/s00268-010-0760-5. 10. Петри А, Сэбин К, ред. Наглядная статистика в медицине. Леонов ВП, пер. с англ. Москва, РФ: ГЭОТАР-МЕД; 2003. 144 с.

11. Паламарчук ВИ, Шуляренко ВА, Сиряченко ВГ, Игнатов ИН, Шуляренко ОВ. Способ тотальной экстраперитонеальной герниопластики. Патент №102998 Украина. 25.11.2015.

12. Lau H, Patil NG, Yuen WK, Lee F.Urinary retention following endoscopic totally extraperitoneal inguinal hernioplasty. Surg Endosc. 2002 Nov;16(11):1547-50.

13. Bittner R, Schmedt CG, Leibl BJ. Transabdominal preperitoneal approach. In: LeBlanc KA. Laparoscopic hernia surgery. London, UK: Arnold Publisher; 2003. p. $54-64$. 
14. Lau H, Loong F, Yuen WK, Patil NG. Management of herniated retroperitoneal adipose tissue during endoscopic extraperitoneal inguinal hernioplasty. Surg Endosc. 2007 Sep;21(9):1612-16.

15. Nasr AO, Tormey S, Walsh TN. Lipoma of the cord and round ligament: an overlooked diagnosis? Hernia. 2005 Oct;9(3):245-47.

\section{REFERENCES}

1. Aver'ianov MIu, Gaar EV, Gorokhov VN. Sravnitel'nyi analiz primeneniia nenatiazhnykh i traditsionnykh sposobov gernioplastiki pri gryzhakh zhivota [Comparative analysis of the use of tension-free and the traditional methods of hernioplasty with abdominal hernias]. Sovrem Tekhnologii v Meditsine. 2011;(3):39-43.

2. VinnikIuS, Petrushko SI, Gorbunov NS, Nazar'iants IuA. Operativnoe lechenie gryzh perednei briushnoi stenki [Surgical treatment of hernias of the anterior abdominal wall]. Krasnoiarsk, RF; 2011. 260 p.

3. Saclarides TJ, Myers JA, Millican KA, eds. Common surgical diseases: an algorithmic approach to problem solving. 3-rd ed. New York, US: Springer; 2015. $363 \mathrm{p}$.

4. Nikolaev NE, Alekseev SA. Klassifikatsiia, etiopatogenez i vybor sposobov khirurgicheskogo lecheniia pakhovoi gryzhi [Classification, etiopathogenesis and the choice of methods of surgical treatment of inguinal hernia]. Zdravookhranenie. 2014;(12):36-39.

5. Vizgalov SA, Smotrin SM. Pakhovye gryzhi: sovremennye aspekty etiopatogeneza i lecheniia [Inguinal hernia: current aspects of pathogenesis and treatment].

Zhurn Grodn Gos Med Un-ta. 2010;(4):17-22.

6. Pinevich DL, Sukonko OG, Poliakova SL, Smirnov VM, Minich AA. Printsipy «khirurgii uskore-

\section{Адрес для корреспонденции}

04112, Украина, г. Киев, ул. Дорогожицкая, д. 9, кафедра хирургии

и сосудистой хирургии, тел. раб.: +380 444 32-24-52,

e-mail: oleg.v.shu@gmail.com,

Шуляренко Олег Владимирович

\section{Сведения об авторах}

Шуляренко О.В., к.м.н., доцент кафедры хирургии и сосудистой хирургии Национальной медицинской академии последипломного образования имени П.Л. Шупика nnogo vyzdorovleniia» [The principles of "surgery rapid recovery"]. Zdravookhranenie. 2014;(5):34-48.

7. Nichitailo ME, Bulik II. Sovremennye aspekty endovideokhirurgicheskogo lecheniia slozhnykh i retsidivnikh pakhovykh gryzh [Modern aspects endovideosurgical treatment of complex and recurrent inguinal hernias]. Klin Khirurgiia. 2010;(3):10-16.

8. Zhebrovskii VV. Khirurgiia gryzh zhivota. Moscow, RF: Med Inform Agentstvo; 2005. 384 p.

9. Tam KW, Liang HH, Chai CY. Outcomes of staple fixation of mesh versus nonfixation in laparoscopic total extraperitoneal inguinal repair: a meta-analysis of randomized controlled trials. World J Surg. 2010 Dec;34(12):3065-74. doi: 10.1007/s00268-010-0760-5.

10. Petri A, Sebin K, red. Nagliadnaia statistika v meditsine [Visual statistics in medicine]. Leonov VP, per. s angl. Moscow, RF: GEOTAR-MED; 2003. 144 p.

11. Palamarchuk VI, Shuliarenko VA, Siriachenko VG, Ignatov IN, Shuliarenko OV. Sposob total'noi ekstraperitoneal'noi gernioplastiki [A method of total extraperitoneal hernia repair]. Patent №102998. Ukraina. 25.11.2015.

12. Lau H, Patil NG, Yuen WK, Lee F.Urinary retention following endoscopic totally extraperitoneal inguinal hernioplasty. Surg Endosc. 2002 Nov;16(11):1547-50.

13. Bittner R, Schmedt CG, Leibl BJ. Transabdominal pre-peritoneal approach. In: LeBlanc KA. Laparoscopic hernia surgery. London, UK: Arnold Publisher; 2003. p. 54-64.

14. Lau H, Loong F, Yuen WK, Patil NG. Management of herniated retroperitoneal adipose tissue during endoscopic extraperitoneal inguinal hernioplasty. Surg Endosc. 2007 Sep;21(9):1612-16.

15. Nasr AO, Tormey S, Walsh TN. Lipoma of the cord and round ligament: an overlooked diagnosis? Hernia. 2005 Oct;9(3):245-47.

\section{Address for correspondence}

04112, Ukraine, Kiev, st. Dorogozhytska, 9, National Medical Academy of Postgraduate Education named after PL Shupyk, department of surgery and vascular surgery. Tel: +380 444 32-24-52

E-mail: oleg.v.shu@gmail.com

Shulyarenko Oleg Vladimirovich

\section{Information about the authors}

Shulyarenko O.V. PhD, Ass. Professor, National Medical Academy of Post-graduate Education named after P.L. Shupyk, department of the surgery and vascular surgery. 